\title{
Greenhouse policy persuasion: towards a positive theory of discounting the climate future
}

\author{
Ernst Mohr * \\ Institute for Economy and the Environment, University of St. Gallen, St. Gallen, Switzerland
}

Received 14 January 1995; accepted 29 June 1995

\begin{abstract}
The climate policy issue is in a state where different visions or proposals compete with one another in the political arena. The success of such a vision or proposal largely depends on the success of its proponents in persuading the public or a yet undecided ultimate authority of its merits. This essay identifies a discounting related ambiguity in cost-benefit analyses of climate change, making two competing visions and proposals "legitimate." By placing the induced opportunity for greenhouse policy persuasion in a political economy context, it is shown how visionaries and lobbyists can exploit human time preferences for the purpose of greenhouse policy persuasion.
\end{abstract}

Keywords: Public investment; Cost-benefit analysis; Climate policy; Persuasion; Social discount rate; Psychological framing

\section{Introduction}

In these days of firm conviction and advice as to what is a good or even the right amount of greenhouse gas abatement, it is not easy to confess that one does not know. Yet there is consolation awaiting the crowd of those who are undecided-they are important for the greenhouse visionaries and lobbyists. This is because visionaries and lobbyists do not only seem to know which climate policy society should choose; they also are aware that their advice can only turn policy if they can convince the undecided and gain their support.

\footnotetext{
* Correspondence address: IWÖ-HSG, Tigerbergstrasse 2, CH9000 St. Gallen, Switzerland. Tel.: $(+41-71) 302719$; fax: $(+41$ 71) 229379 .
}

This essay is an exploration of the matter of greenhouse policy persuasion. It is an investigation into understanding how the debate on the right climate policy is being propelled. In particular, amongst several factors which are important for this debate, the essay focusses on the issue of discounting the climate future.

The investigation is not an empirical one. An empirical study could indeed shed light on this question by examining, in the fashion of literary critique, how arguments for or against climate protection are exchanged in scientific and political circles and how they are posed to the public. However, this essay confines itself to a micro-economic investigation.

In economics we became accustomed to the idea that people behave in the interest of their well-being in some rational way. It is a fact of life, though, that our human well-being not only depends on the mun- 
dane consumption of goods and commodities, but also on our success in convincing others of our beliefs. It also appears obvious that lobbies can promote their interests not only by opening their wallets, but also by making a good point. It is then a straightforward extension of economics to become accustomed to the idea that lobbyists and people with beliefs behave rationally when persuading others to adopt their beliefs or plans. This essay is an attempt to break some of that ground.

The approach pursued in this essay is much more limited than and different from Donald McCloskey's Rhetoric of Economics (McCloskey, 1986). The focus is not on an understanding of how economists persuade each other and what makes good and successful writing in economics. The focus is on placing the need for and the act of persuasion in a political economy context such as is done in a much broader context in Meier and Slembeck (1994). This focus is of interest for economics if, as one could argue, real life decisions, like public policy making (but also those within the private sector), depend in part on acts of persuasion. ${ }^{1}$ An understanding of persuasion may then help us to further understand these decisions.

This investigation is accessible to micro-economic analysis. All one needs are a few standard assumptions concerning human behaviour. Amongst these are the assumption of goal oriented behaviour on the part of those who persuade, and the assumption that those who are the target of persuasion exhibit a degree of intellectual sophistication neither below nor beyond the standard consumer who is usually taken to be able to solve moderately complicated choice problems. To that end it will be presumed that the ultimate authority in this society is sophisticated enough to think of the climate (policy) issue in terms of gains and costs. Endowed with this degree of intellectual sophistication, the target of persuasion evaluates the arguments the other side puts forward in the process of persuasion. A predictive power of this approach is possible if the intellectual black box inside the target of persuasion, in which arguments

\footnotetext{
${ }^{1}$ McCloskey (1994), p. 79) estimates, for example, that the persuasion "sector" in the US economy is responsible for roughly a quarter of national product.
}

are evaluated, is filled with some real world attributes of human beings, exploitable for persuasion.

A further presumption is that making one's own vision or one's clientele's interests win requires a solid amount of persuasion under conditions of argumentative competition. The visionaries or lobbyists must convince a king, oligarchy, or the voters, in order to have their policy proposal implemented.

It has been widely acknowledged that a central problem with evaluating greenhouse policy alternatives is discounting (e.g., Pearce, 1991). I argue accordingly that the discounting issue is the master key to greenhouse policy persuasion. This essay presents a predictive analysis of how greenhouse visionaries and lobbyists discount the climate future. The next section gives a sketch of the argument.

\section{Overview of the argument}

The application of cost-benefit calculation to climate policies, though in principle a good approach from an economist's perspective, is burdened with a discounting fuzziness greater than that with other public investment problems. This is because the time delay between today's policy decision and its future effects is extremely long in the case of greenhouse policy and climate change. A small variation in the discount rate applied has therefore a large effect on discounted values. This makes several competing greenhouse policy visions or proposals reasonable.

The concept that the present value of future benefits (or costs) will vary with the discount rate used and the period of the analysis is most easily demonstrated through illustration. For example, the present value of a dollar discounted for 20 years at 3 percent is approximately two-times greater than a dollar discounted at 7 percent for the same time period. Over a 200-year time period the differential becomes far greater. For example, the present value of a dollar discounted at 3 percent over 200 years is three orders of magnitude greater than the present value of a dollar discounted at 7 percent over the same time period.

Contesting discounting philosophies can therefore be viewed as one "secret" behind differing competing climate policy advice. All must, however, pass 
the same test on their journey to becoming policy. This test is the ultimate authority's own time preference with which the discounting philosophy is compared. For example, in direct democracy it is the median voter's time preference which counts; and a vision or proposal can only succeed if for given gains and costs, spread out over time, the vision or proposal is compatible with the median voter's own time preferences.

If these time preferences were exogenous, the prediction would be that the visionaries' or lobbyists' discounting philosophy would (ultimately) converge towards the ultimate authority's exogenous time preference; and the issue could already be settled.

Empirical evidence obtained from psychological experiments suggests, however, that human time preferences are endogenous to the problem with which humans are confronted. From a normative perspective this can cause an evaluatory circularity in cost-benefit analyses of climate change. From the perspective of predicting the behaviour of those involved in greenhouse policy persuasion, it follows that due to the endogeneity of human time preferences alone, competing visions and proposals can thrive in the political market. It also follows that visionaries or lobbyists possess a degree of freedom in their choice of discount rate: that is, they can exploit the endogeneity of human time preferences. It is therefore suggested that they will-to the advantage of their own vision or their clientele's interest. By framing the policy problem in a suitable way, and there is more than a single suitable way, visionaries or lobbyists can ensure that the time preferences of the ultimate authority are favourable to their interests.

By placing the normative problem of greenhouse policy making in the context of political opinion making, it is possible to predict how in the market for greenhouse policy argumentation visionaries and lobbyists will seek to persuade. One can show by way of examining the endogeneity of human time preferences in the context of climate change which social rate of discount will be mandated by competing visions or interests and how (i.e., by way of which argumentation) they can make the ultimate authority's own time preferences compatible with their proposed discounting rule.

\section{Fuzziness creates an opportunity for persuasion}

Although the thrust of this essay is to make predictions about techniques of persuasion relating to climate policies, a glance at the normative debate is helpful. The motivation is that when the normative issue remains fuzzy, and reasonable people can therefore disagree, visions can thrive and persuasion gains in terms of importance for those who, for one reason or another, seek to influence public choice.

A standard procedure to find the right amount of investment in a public project is provided by cost-benefit analysis (Johansson, 1993). A number of costbenefit analyses on greenhouse gas abatement or components thereof already exist (notably Cline, 1992; Nordhaus, 1991, 1992; Mendelsohn et al., 1994).

The important point is that even in the presence of complete certainty the discounting problem associated with evaluating the climate future introduces an ambiguity which cannot be resolved. This ambiguity is present, though, in all cost-benefit comparisons in which direct recourse to human time preferences is taken. It is, however, much more troublesome when evaluating greenhouse policies because the "leverage" of discounting is larger in this case than in any other public investment problem due to the extremely large time lags in climate change.

Which social discount rate should be applied to public investment problems has attracted wide attention. The set of papers collected by Lind (1982) provides an overview of that discussion. It remains unsettled. This, together with the leverage which discounting provides in the case of climate change, explains much of the scepticism shown towards cost-benefit comparisons of greenhouse policies. The exercise resembles working the jukebox. The song you hear depends on the button you press. For example, the far-reaching greenhouse policy recommendation in Cline (1992) is based on a 2 percent social discount rate for goods and a risk averse attitude, while the (medium damage) abatement recommendation by Nordhaus (1991), implying only a 2 percent $\mathrm{CO}_{2}$ emission reduction, is based on a rate of 4 percent.

Applied to climate change, various competing discounting philosophies can be identified, but all suggest a departure from the simple rule of using 
observable market rates of discount (consumer rate or investment rate) for evaluating greenhouse policies Marglin, 1963; Sugden, 1985; Lind, 1990; Hueting, 1991; Broome, 1992; Birdsall and Steer, 1993).

All these discounting approaches have one thing in common. They all point to the decisive importance of individual time preferences for the purpose of proceeding with greenhouse policy-making. Unless the discounting philosophies are compatible with the ultimate authority's own time preferences, the induced policy proposals have little chance of survival. In trying to make predictions on climate policy-related issues, it is therefore helpful to look at actual human time preferences in greater detail.

\section{The human intertemporal disposition is intri- cate}

In economic models of human behaviour, individual time preferences are typically represented by an exponential discount function or its discrete time equivalent. Exponential discounting possesses attractive normative properties, but it contradicts experimental findings (Loewenstein and Prelec, 1992) and commonly observed behaviour (Ainslie, 1992). Loewenstein and Prelec report experimental work in which it was found out that, amongst other things, actual human time preferences differ from those which are representable by exponential discounting in the following respects:

1. The Common Difference Effect, implying that the discount rate applied decreases as a function of the time delay, such that, for example, a value obtained in 5 years' time is discounted at an annual rate of 5 percent, and the same value obtained in 6 years' time is discounted at an annual rate of 4 percent.

2. The Absolute Magnitude Effect, implying that large amounts suffer less proportional discounting than do smaller ones, such that, for example, $\$ 10$ obtained in a year are discounted at an annual rate of 10 percent, and $\$ 100$ due on the same day are discounted at 7 percent.

3. The Gain-Loss Asymmetry, implying that losses are discounted at a lower rate than gains, such that, for example, a loss of $\$ 10$ to be incurred in a year is discounted at 5 percent, and the same amount due on the same day is discounted at 7 percent if it is a gain.

From a predictive perspective, these anomalies have relevance if the crucial test, which greenhouse policy proposals must pass is compatibility with human time preferences. From the normative perspective the main question is: "But if individuals do not discount everything at a single rate, then which rate is the one that is appropriate for social discounting?" (Loewenstein and Thaler, 1989, p. 192).

The leverage which discounting provides in the case of climate further adds to the importance of these anomalies. I have no answer to offer as to what is in their presence an appropriate discount rate from a normative perspective. But it is feasible to say something about what is considered appropriate from the point of view of the greenhouse visionaries and lobbyists and, more importantly, how their proposals can pass the crucial test.

The experiments reported by Loewenstein and Prelec represent situations where the stake outstanding ranges from a few dollars to a few thousand dollars, and the time intervals over which test persons must discount ranges from a few days to a few years. I am not aware of any empirical studies that even come close to the minimum time horizon (half a lifetime or more) that climate discounting requires. It remains an open question whether for the climate stakes outstanding and the time horizon involved the empirical findings still hold or whether these anomalies "fade out" when the experiments are adapted more and more to the case of climate. One way of judging whether an investment in the generation of this empirical evidence is worthwhile is to see what the persistence of these anomalies would imply. We therefore next address their implications for the behaviour of rational visionaries and lobbyists.

\section{Greenhouse policy evaluation is necessarily am- biguous and consequently visionary}

The consequences of the Gain-Loss Asymmetry for climate policy evaluation is depicted in Fig. 1. ${ }^{2}$

\footnotetext{
${ }^{2}$ For reasons of graphic exposition, all functional relationships are linearized.
} 
The declining line in quadrant I represents the jukebox nature of cost-benefit analyses of greenhouse policies. The smaller the normative discount rate employed, the larger the recommended greenhouse gas abatement. The test which the policy recommendation and the underlying normative discount rate must pass is represented by the $45^{\circ}$-line in quadrant II. It ensures compatibility of the normative discount rate employed in the evaluation of policies with human time preferences. Quadrants I and II read as saying that action $\mathrm{A}^{*}$ is legitimized by individual time preferences $A$, whereas the smaller action $B^{*}$ is legitimized by the larger time preference $B$. The Gain-Loss Asymmetry introduces an unavoidable ambiguity into cost-benefit analyses of climate change. This is because the exercise can be undertaken in two (equally legitimate) ways, one, however, mandating policy $\mathrm{B}^{*}$, say, and the other policy $A^{*}$. To that end, suppose in accordance with the Gain-Loss Asymmetry that the representative individual discounts a gain at the rate $B$ and a loss at the rate $A$, with $B>A$, as in Fig. 1 .

Consider first the exercise which leads to the recommendation of policy $B^{*}$. We can frame the policy problem in the following way. Starting from a status quo of doing nothing about global warming (the business-as-usual reference case), we could ask what are the gains and losses of sequentially, but marginally increasing our climate protection efforts. In this frame we must compare additional costs of abatement efforts that we must bear today with additional gains from a somewhat lesser degree of warming that we can enjoy sometime in the (far) future. That is to say, in this frame we discount gains. If our discounting rule requires the application of a discount rate which is compatible with human time preferences as they actually are, then we are induced to apply in our example the discount rate $\mathrm{B}$ to the cost-benefit calculation; and we consequently end up with recommendation $\mathrm{B}^{*}$.

To demonstrate the ambiguity introduced by the Gain-Loss Asymmetry, consider a second frame in which we could evaluate policies. Instead of departing in our exercise from business as usual, we could start from any hypothetical abatement effort, such as $\mathrm{C}^{*}$ in Fig. 1. Suppose, for example, $\mathrm{C}^{*}$ is the abatement level which limits the greenhouse gas concentration to the present level and thus constrains warming to what has been already committed to in the past. We can then ask what are the gains and losses of sequentially but marginally decreasing our climate protection efforts. But in this frame we compare gains (of doing less than $\mathrm{C}^{*}$ against warming) which we can enjoy today with losses (from suffering from more warming) which we will have to bear in the future. In this frame we discount losses. If the social discount rate applied to this cost-benefit comparison must be consistent with human time preferences in this situation, we must apply the discount rate $A$ and end up with recommendation $\mathrm{A}^{*}$.

The gain-loss asymmetry induces an evaluatory

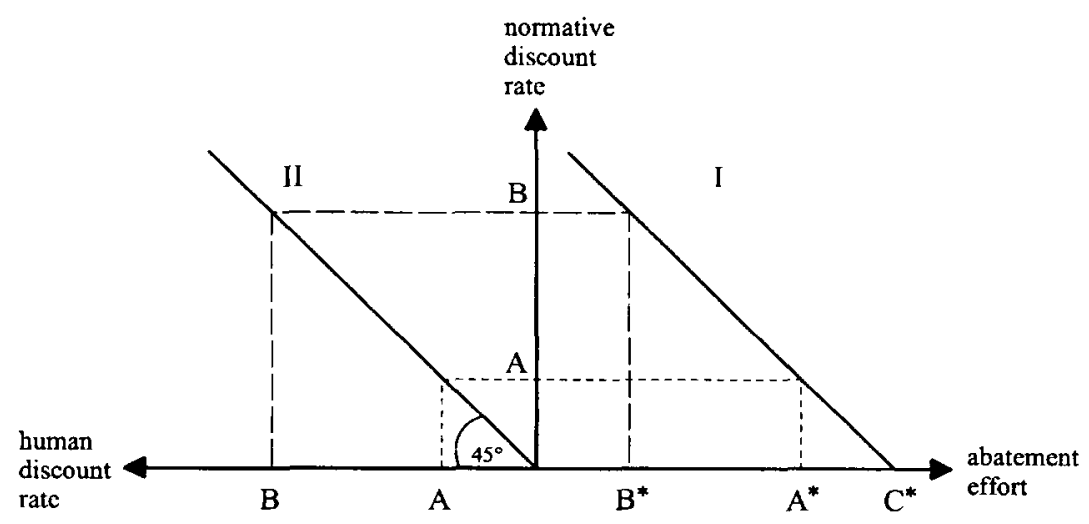

Fig. 1. Gain-Loss Asymmetry and cost-benefit discounting. 
circularity in which different policies can be legitimized by different but similarly reasonable mental exercises. The problem of evaluatory circularity in public choice has long been recognized (Scitovsky, 1941) and the scope of the problem recently stressed (Penz, 1986; Cowen, 1993). With respect to the normative dimension, the above consideration merely adds another example to a sizable list. But in contrast to some other cases of evaluatory circularity, preferences do not change with a change in policy. Rather, for any policy the individual always exhibits two variants of time preferences.

Note that the framing of the exercise would be irrelevant for the policy conclusion if a Gain-Loss Asymmetry did not exist (i.e., if $\mathrm{A}=\mathrm{B}$ ). But in the presence of the ambiguity the frame in which the exercise is undertaken matters. What is cumbersome in its presence is that it appears difficult to discriminate normatively between the frames. My hunch is that it is impossible to do so.

Whether the future event is framed as a gain or a loss depends on the reference point of the cost-benefit exercise. In the exercise leading up to recommendation $\mathrm{B}^{*}$ the reference point is the origin in Fig. 1; in the alternative exercise leading to the recommendation of $\mathrm{A}^{*}$ it is $\mathrm{C}^{*}$. The importance of reference points for actual intertemporal decision making by individuals has been demonstrated by Loewenstein (1988) who concludes that "framing is of consequence for decision theorists because it suggests that subtle changes in decision presentation ... can result in significant shifts of choice"' (p. 201). One is inclined to object to all this by asking whether a statement which relates to a positive analysis of decision making has any bearing on a normative problem of social choice. After all, normative decision theory requires that choice should be made on the basis of final levels of wealth or well-being and not on the basis of differences from a reference point. Quite so, but if the representative individual casts intertemporal problems in relation to a reference point, and, if in departing from it, it matters to him or her whether it is a gain or a loss, we are led back to Loewenstein and Thaler's main question, if we elevate actual human time preferences to the normative level.

The identified ambiguity raises the question of how democratic choice can maintain its normative appeal if it crucially depends on how the items on the ballot are formulated or which psychological disposition is engraved by the campaign. Passing from the normative to the positive dimension, we can draw the summary conclusion that the unresolved and perhaps unresolvable normative debate feeds both the need for and the needs of the visionaries and lobbyists. The normative stalemate creates an opportunity for visionaries and lobbyists alike to pursue their interest.

The remainder of this essay is devoted to some implications that actual human intertemporal dispositions may have for the behaviour of agents in the area of public opinion and policy making when the issue involves intertemporal cost-benefit comparison. There already exist a number of contributions to this field.

Lewis and Cullis (1988) identify a general deficiency in taking account of psychological aspects in analyses of public choice. The necessity of taking psychological aspects into account in cost-benefit analyses has been voiced by Earl (1990, p. 743). Ulen (1990) applies findings from cognitive psychology to an economic analysis of legal rules. Brembeck (1991) provides an analysis of congressional deficit spending from a psychological perspective. But closest to the approach explored in the present essay is the remark by Crocker and Shogren (1993, p. 252) that environmental advocates could exploit the Gain-Loss Asymmetry in intertemporal choice in the interest of efficient lobbying.

For an understanding of greenhouse activism, argumentation, and policy recommendations, it is of considerable interest to track the consequences of human intertemporal disposition. Of particular interest is how advocates of a certain greenhouse policy, the visionaries and lobbyists, can persuade the ultimate authority of the merits of their proposal.

Before turning to that, two remarks are due. One, the term "visionary" is not meant derogatorily. Heilbroner (1990), adopting Schumpeter's definition of a vision as the "preanalytic cognitive act" (p. 1109), provides an impressive account of the visionary nature of respected contributions to economics. We can transpose this respectful attitude to the realm of politics, yet ask how visionaries and lobbyists can persuade.

Two, in political economy lobbyism is mainly 
equated with the process of party or incumbency financing or bribing (e.g., Grossman and Helpman, 1994). With this preponderance, another instrument of lobbying, which I consider just as important, is obscured. Lobbies seem to engage in providing argumentative ammunition for those in favour of their interests, and to bombard their foes with same, as much as they are engaged with pulling out the wallet. Irrespective of whether good arguments are complements or substitutes for cash, if lobbies possess them, or if they can make them up at decent costs, it would be uneconomical to hold them back.

\section{The endogeneity of time preferences is a key to persuasion}

Greenhouse policy visions and proposals sometimes take the form of exact abatement recommendations, but more often that of ordinal orderings of alternatives. Competition between visions and proposals is accordingly often voiced in terms of whether climate policy should be "far reaching" and "decisive" or rather should "not overreact" and pay "'heed to present societal constraints," intoning that a lot of abatement is better than little and vice versa. Accordingly, the supply side of the market for greenhouse policy visions and proposals seems to have consolidated into two camps, competing with each other on these broad terms.

In practice, the task of a visionary or lobbyist is to convince the ultimate authority of the validity of such a broad statement and of the deficiency of the alternative rather than of an exact time path of abatement. The problem with this task appears to be that the ultimate authority will judge by itself in terms of perceived costs and gains, spread out over time. The good luck is that the visionary can seek to influence this judgement by a suitable exploitation of the endogeneity of time preferences. A rational visionary or lobbyist will not hesitate to do so.

If we call, for want of better terms, the visionary or lobbyist who favours "little" abatement to "large" abatement the conservative persuader, and the one who prefers a "lot" of abatement effort to "little" effort the green persuader, we can make the following predictions:
1. The conservative persuader will frame the public choice problem in terms of current costs of climate protection and of future gains thereof, while the green persuader will seek to speak of the future costs of remaining idle now, so that the immediate effect is the gain from doing nothing.

2. The conservative persuader exhibits a general tendency to "round" down future effects (be they in terms of costs or benefits), while the green persuader shows a tendency of "rounding" up future effects.

3. The conservative persuader exhibits a tendency to direct attention to the shorter term; the green persuader seeks to stress the long-term nature of the climate problem.

Prediction (1) is an immediate consequence of the Gain-Loss Asymmetry explored in Fig. 1. By framing the problem in terms of future gains and present costs, the ultimate authority is induced by the conservative persuader to apply the (larger) discount rate for gains to the problem, which is in favour of the conservative vision and proposal (policy B ${ }^{*}$ in Fig. 1). Likewise, the green persuader persuades the ultimate authority into greater action ( $\mathrm{A}^{*}$ in Fig. 1) by framing the issue so that the authority applies the (smaller) discount rate for losses.

Predictions (2) and (3) require further justification. First, it should be noted that each of these predictions can be defended by a trivial and a more subtle argument. The trivial one recalls the fact that the larger the future effect, the larger is the economic incentive to act today (to mitigate the negative effect or foster the positive). In the same manner, the shorter the time horizon, the more future effects are taken out of calculation and the larger is the economic incentive to do little today. For these reasons alone, the green persuader seeks to assure a long time horizon and to round up effects; and the conservative one will seek the opposite.

But there is an additional, less obvious reason justifying these predictions. It is valid in a situation of uncertainty concerning the time lag and magnitude of future effects and it draws on the Absolute Magnitude Effect and the Common Difference Effect of human intertemporal disposition.

Consider the Absolute Magnitude Effect. By rounding down (uncertain) future effects the conservative persuader induces the ultimate authority to 
apply a higher discount rate to the problem. Likewise, the green persuader can induce a lower discount rate to be applied by rounding up future effects. Thereby the visionaries and lobbyists contribute to the persuasiveness of the arguments behind their personal proposal and discredit the alternative.

The Common Difference Effect can be exploited for the same purpose. If the conservative persuader succeeds in keeping the ultimate authority's attention away from the distant future (exploiting the scientific uncertainty concerning time lags), a higher discount rate is applied which favours the conservative proposal. In as much as the green persuader succeeds in guiding the ultimate authority's attention to the long term, a lower discount rate, more favourable to the green vision and proposal, is induced.

There is an important difference between prediction (1), on the one hand, and predictions (2) and (3) on the other. Prediction (1) can be maintained under ideal circumstances where all uncertainty is resolved. Under this condition both the magnitude of future effects and the time of their occurrence is uncontroversial. An argumentative fiddling with them would therefore not be persuasive. But under more realistic circumstances, and closer to what we shall have to bear with for the time being, there is considerable uncertainty about the magnitude and time of future greenhouse effects. For the time being, predictions (2) and (3) remain relevant.

In Fig. 2 the consequences of the simultaneous occurrence of the Gain-Loss Asymmetry and the Absolute Magnitude Effect are depicted. To isolate them from the Common Difference Effect, suppose that the future effect of climate change will occur at a single uncontroversial point in time. Fig. 2 is an extension of Fig. 1 for quadrants III and IV.

The lines in quadrant IV represent the relationship between the abatement effort made in the present and the magnitude of the future (climate) effect in current money terms. As before, let $\mathrm{C}^{*}$ be the abatement effort which keeps greenhouse gas concentration at the present level, thus constraining warming to the (precommitted) minimum. Each line in quadrant IV is associated with a particular cognitive frame. The line labelled "(loss)" is associated with the frame which gives the future effect in terms of losses; the line labelled "(gain)" is associated with the cognitive frame which implies future gains.

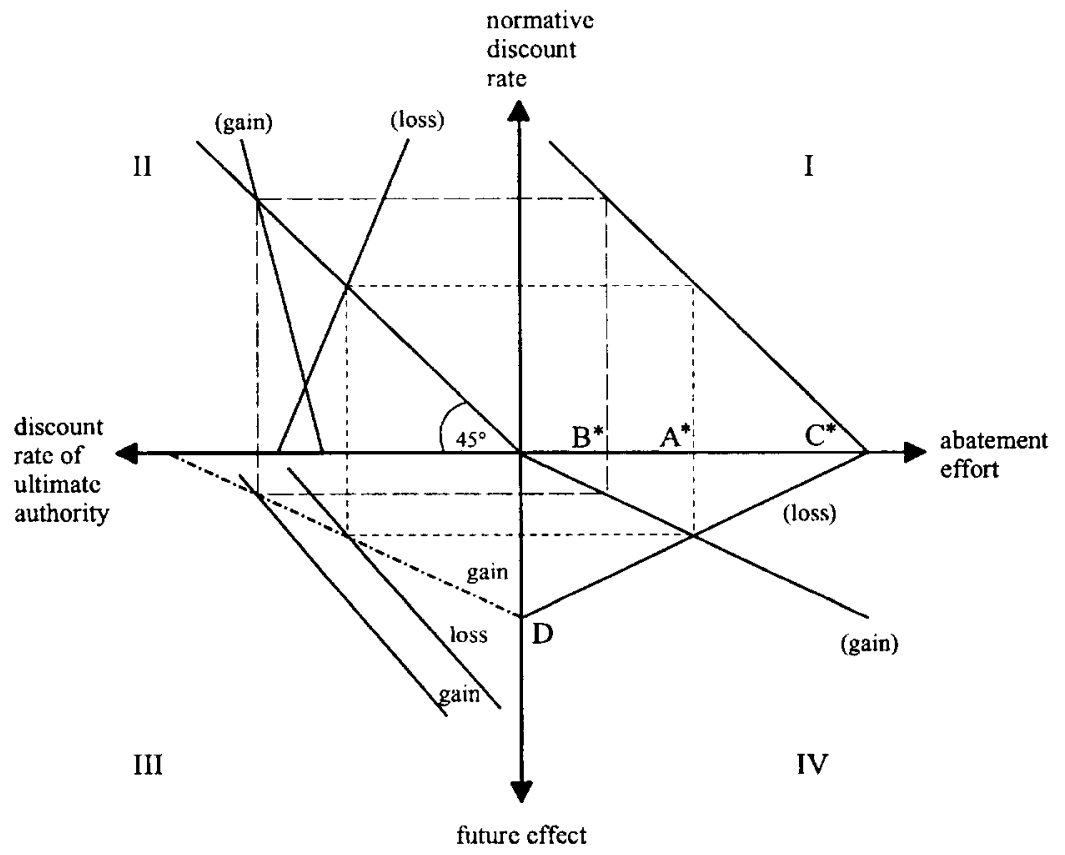

Fig. 2. Persuasive discounting. 
The slope of the line ending in $\mathrm{C}^{*}$ represents the fact that a reduction in abatement effort, leading to an increase in greenhouse gas concentration, induces the future average temperature to increase further, thus inducing a larger future loss in current money terms. Therefore, D is the future loss associated with the business-as-usual scenario of doing nothing against warming. The slope of the line starting at the origin represents the fact that an increase in abatement effort, reducing concentration, induces the future average temperature to rise less, thus causing a larger future gain in current money terms. When abatement level $\mathrm{C}^{*}$ is attained, that gain is as large as D.

The combined effect of the Absolute Magnitude Effect and the Gain-Loss Asymmetry on human intertemporal disposition is given by the sloping solid lines in quadrant III. For any size of future effect the discount rate applied to gains exceeds that for losses, but for each cognitive frame the rate declines as the future effect increases. The lines in quadrant II, other than the $45^{\circ}$-line, represent the relationship between the normative discount rate, consistent with a certain abatement proposal, and the induced time preferences of the ultimate authority. It depends, of course, also on the induced cognitive frame. To understand the construction of the graphs in quadrant II, consider the one labelled "(gain)." Starting from any normative discount rate, we obtain via the graph in quadrant $I$ an induced abatement effort. If the cost-benefit exercise is framed in terms of future gains, the graph in quadrant IV labelled "(gain)" gives the induced magnitude of the future effect of the policy supported by the chosen normative discount rate, and from the discount function for gains in quadrant III we obtain the endogenous human discount rate as induced by the policy proposal and the frame chosen. The graph labelled "'gain)" in quadrant II is therefore the locus of human intertemporal dispositions induced by arbitrary normative discount rates and the cognitive frame which takes future effects as gains. The construction of the other graph in quadrant II is isomorphic.

The intersection of each of these graphs in quadrant II with the $45^{\circ}$-line gives the abatement proposals which pass the societal test, if the right frame is chosen. Fig. 2 gives the case in which an intersection exists for each frame. In this case, the conservative persuader can make a strong case against abatement efforts in excess of $B^{*}$, such as $A^{*}$, if it frames the problem in terms of future gains. Again, the green persuader prefers to frame the problem in terms of future costs, allowing him to make a strong case against abatement efforts below $\mathrm{A}^{*}$.

Note that the two quadrants on the right of Fig. 2 can be thought of as representing the science and economics constraints on greenhouse policy persuasion. If observed, they insulate a proposal against scholarly critique. Quadrant III represents the set of psychological states the persuader can generate. It is instrumental. Quadrant II represents the public dimension of public policy persuasion. The lines linking the normative and actual discount rates are the tradeoffs a persuader faces between the normative claim and its persuasiveness. The $45^{\circ}$-line ensures that the supply side of persuasion heeds the preferences of those to be persuaded.

The societal test of quadrant II may altogether fail to restrain the persuader. For the purpose of considering this assertion, note that the dashed graph in quadrant III gives the relation between future effects (framed in terms of gains) and actual time preferences, such that the normative discount rate, underlying any abatement proposal, is the same as the actual discount rate on the side of the ultimate authority induced by the proposal, if framed in terms of future gains. Hence, if the human time preferences if framed in terms of future gains are given by the dashed line in quadrant III, then any abatement proposal passes the test. More generally, if human time preferences can be approximated by the dashed line, then the human intertemporal disposition is too putty-like to produce solid results from the societal test. In this case there remains, of course, no incentive on the part of the green persuader to frame the problem in terms of future costs. Both will use the other frame and work the jukebox without constraint.

\section{Conclusions}

This paper applied a micro-economic approach to the issue of public opinion and policy generation. It narrowed the issue down to a problem of persuasion. The economic interpretation of this kind of social activity has drawn on the notion of rational be- 
haviour of agents who seek to persuade persons of importance for public choice under a set of restrictions and opportunities. These restrictions were that persuasiveness required an argument to be (scientifically) consistent and, inasfar as it involves (intertemporal) value judgements, the persuader needed to heed the (intertemporal) preferences of those whom it desired to persuade. The opportunities for persuasion have been derived from the experimental observation that human (time) preferences are not exogenously given, but are context-dependent and can be systematically exploited for rational persuasion.

Within this analytical framework the paper derived predications concerning the argumentative behavior of greenhouse policy persuaders. It was shown that persuaders proposing minimal abatement efforts will have an incentive to cast the problem in a mental context which is different from the that preferred by a persuader who wants to persuade people into making large abatement efforts. The differences identified allow the identification of persuaders whose intentions are a priori unknown. A troubling implication of the analysis is that public policy persuasion cannot achieve the reduction of competing climate policy proposals to a single proposal that is convincing.

The analysis was made entirely from the example of climate policy persuasion. Obviously, the scope for an investigation of persuasion, when intertemporal evaluation is important, goes beyond the climate problem. Other (public) investment problems may also be subject to this kind of persuasion. The arguments have focused on the case of climate because if the thread laid out in this essay is not relevant to greenhouse policy, it is unlikely to be relevant elsewhere.

\section{Acknowledgements}

I would like to thank Robert E. Unsworth for very valuable comments on an earlier version of the paper.

\section{References}

Ainslie, G., 1992. Picoeconomics. Cambridge University Press, Cambridge.
Birdsall, N. and Steer, A., 1993. Act now on global warming-but don't cook the books. Finance Dev., 30: 6-8.

Brembeck, C.S., 1991. Congress, Human Nature, and the Federal Debt. Praeger, New York, NY.

Broome, J., 1992. Counting the Cost of Global Warming. The White Horse Press, Cambridge.

Cline, W., 1992. The Economics of Global Warming. Institute for International Economics, Washington, DC.

Cowen, T., 1993. The scope and limits of preference sovereignty. Econ. Philos., 9: 253-269.

Crocker, T.D. and Shogren, J.F., 1993. Dynamic inconsistency in valuing environmental goods. Ecol. Econ., 7: 239-254.

Earl, P.E., 1990. Economics and psychology: a survey. Econ. J., 100: 718-755.

Grossman, G.M. and Helpman, E., 1994. Protection for sale. Am. Econ. Rev., 84: 833-850.

Heilbroner, R., 1990. Analysis and vision in the history of modem economic thought. J. Econ. Lit., XXVIII: 1097-1114.

Hueting, R., 1991. The use of the discount rate in a cost-benefit analysis for different uses of a humid tropical forest area. Ecol. Econ., 3: 43-57.

Johansson, P.-O., 1993. Cost-Benefit Analysis of Environmental Change. Cambridge University Press, Cambridge.

Lewis, A. and Cullis, J. 1988. Preferences, economics and the economic psychology of public sector preference formation. J. Behav. Econ., 17: 19-33.

Lind, R.C. (Editor), 1982. Discounting for Time and Risk in Energy Policy. Resources for the Future, Washington, DC.

Lind, R.C., 1990. Reassessing the government's discount rate policy in light of new theory and data in a world economy with a high degree of capital mobility. J. Environ. Econ. Manage., 18: S8-S28.

Loewenstein, G.F., 1988. Frames of mind in intertempral choice. Manage. Sci., 34: 200-214.

Loewenstein, G. and Thaler, R.H., 1989. Anomalies: intertemporal choice. J. Econ. Perspect., 3: 181-193.

Loewenstein, G. and Prelec, D., 1992. Anomalies in intertemporal choice: evidence and an interpretation. Q. J. Econ., CVII: 573-597.

Marglin, S.A., 1963. The social rate of discount and the optimal rate of investment. Q. J. Econ., 77: 95-111.

McCloskey, D.N., 1986. The Rhetoric of Economics. Harvester Wheatsheaf, Brighton.

McCloskey, D.N., 1994. Knowledge and Persuasion in Economics. Cambridge University Press, Cambridge.

Meier, A. and Slembeck, T., 1994. Wirtschaftspolitik: Ein kognitiv-evolutionärer Ansatz. Oldenbourg, München.

Mendelsohn, R., Nordhaus, W. and Shaw, D., 1994. The impact of global warming on agriculture: a ricardian analysis. Am. Econ. Rev., 84: 753-771.

Nordhaus, W., 1991. To slow or not to slow: the economics of the greenhouse effect. Econ. J., 101: 920-927.

Nordhaus, W., 1992. Rolling the "DICE': an optimal transition path for controlling greenhouse gases. Resource Energy Econ., 15: $27-50$.

Pearce, D., 1991. Internalising long term costs. Global warming and intergenerational fairness. In: T. Hanisch (Editor), A 
Comprehensive Approach to Climate Change. CICERO, Oslo, pp. 19-31.

Penz, G.P., 1986. Consumer Sovereignty and Human Interests. Cambridge University Press, Cambridge.

Scitovsky, T., 1941. A note on welfare propositions in economics. Rev. Econ. Stud., 9: 77-88.
Sugden, R., 1985. Why be consistent? A critical analysis of consistency requirements in choice theory. Economica, 52: $167-183$.

Ulen, T.S., 1990. The theory of rational choice, its shortcomings, and the implications for public policy decision making. Knowledge: Creation, Diffusion, Utilization; 12: 170-198. 